\title{
Lanthanum Inhibits Surfactant Secretion Stimulated by Lung Distension in Newborn Rabbits
}

\author{
ANTHONY CORBET AND MARILYN OWENS \\ Department of Pediatrics, Baylor College of Medicine, Houston, Texas 77030
}

\begin{abstract}
The effect of lanthanum on lung phospholipid secretion stimulated by lung distension was examined in 29.5-d gestation newborn rabbits. Lung lavage with saline alone produced $608 \pm 109 \mu \mathrm{g}$ phospholipid/lung (mean \pm SEM), whereas lavage with $10^{-3} M$ lanthanum produced only $153 \pm 40 \mu \mathrm{g}$ phospholipid/lung $(p<0.05)$, the difference in yield being attributed to inhibited lavageinduced secretion with lanthanum. If this interpretation is correct, then an increased residual tissue surfactant should be found in lanthanum-lavaged lungs. Postlavaged lung was separated into IA, IB, and IC fractions by homogenization and then centrifugation with 0.25 and $0.65 \mathrm{M}$ sucrose. The surfactant IB fraction was $763 \pm 65 \mu \mathrm{g}$ phospholipid/g wet lung for saline-lavaged lungs, but $1002 \pm$ $90 \mu \mathrm{g}$ phospholipid/g wet lung for lanthanum-lavaged lungs $(p<0.002)$. This confirms that decreased secretion with lanthanum was associated with increased residual surfactant in postlavaged lung. It is concluded that lanthanum is a potent inhibitor of surfactant secretion stimulated by lung distension. (Pediatr Res 30: 190-192, 1991)
\end{abstract}

The pulmonary surfactant is a lipoprotein complex synthesized and secreted by granular pneumocytes, and is necessary for stabilization of lung alveoli during exhalation. Although many factors may modulate secretion of surfactant, it is thought that lung distension is the principal stimulus (1). In newborn rabbits, we have suggested that increased intracellular calcium may be responsible for surfactant secretion induced by distension during lung lavage, because secretion is stimulated by increased calcium in the solution used to lavage the lungs (2). Previous work in our laboratory has demonstrated that lanthanum, an ion that blocks calcium entry into cells (3), inhibits the secretion of surfactant induced by lung lavage, the inhibition increasing with the concentration of lanthanum in the lavage fluid (4). Because the inhibition of secretion was large, the aim of our study was to confirm the inhibitory effect of lanthanum on surfactant secretion, by demonstrating a change in the residual tissue surfactant of postlavaged lung. We found that lanthanum produced both a decrease in lavage phospholipid and an increase in the tissue surfactant fraction.

\section{MATERIALS AND METHODS}

Preliminary experiments indicated that two litters of newborn rabbits would be required to demonstrate statistically significant differences for lavage fluid phospholipid between control and

Received September 24, 1990; accepted April 22, 1991.

Correspondence and reprint requests: Dr. Anthony Corbet, Department of Pediatrics, Baylor College of Medicine, Texas Medical Center, Houston, TX 77030.

Supported by National Institutes of Health Research Resources Division Gran RR-05425. experimental groups and that at least four litters would be required to demonstrate significant differences for tissue surfactant phospholipid.

The litters of seven pregnant New Zealand White rabbits (Ray Nichols Rabbitry, Beaumont, TX) were used in these experiments. Does of $29.5 \mathrm{~d}$ gestation, time of mating known to within $3 \mathrm{~h}$, were anesthetized with methoxyflurane, and then pups were delivered in sequence by hysterotomy. After breathing room air for $30 \mathrm{~min}$, the pups were killed with an injection of pentobarbital $(20 \mathrm{mg})$. Each dead newborn rabbit was weighed, a tracheostomy tube was ligated in place, and the lungs were deflated by vacuum in preparation for lung lavage. Only the first six pups in each litter were used for these experiments, because only six samples could be processed at any one time.

In all experiments, the lungs of alternate pups were lavaged with physiologic saline containing $10^{-3} \mathrm{M}$ lanthanum chloride, and the lungs of the other alternate pups were lavaged with saline alone. Thus, the experimental and control groups always consisted of littermate neighbor pairs, one experimental and one control.

The lavage procedure consisted of 10 successive washes. For each wash, fresh solution at room temperature was used; the volume instilled into the lung and immediately withdrawn was $1 \mathrm{~mL} / 20 \mathrm{~g}$ body weight, estimated to represent two thirds of total lung capacity. Each wash during lavage took $1.5 \mathrm{~min}$ to complete, so the lavage procedure lasted $15 \mathrm{~min}$. The volume of each pooled lavage sample was measured, and it was found that recovery was better than $90 \%$ for all samples.

The uncentrifuged lavage samples from the first two litters were analyzed for phospholipid after storage overnight at $4^{\circ} \mathrm{C}$. For the measurement of phospholipid, lipids were extracted in chloroform-methanol, and phosphorus was assayed as previously described (5). Results were expressed as $\mu \mathrm{g}$ phospholipid/lung.

The tissue surfactant fraction of lavaged lung from all litters was analyzed using the method described by Frosolono (6). The lung was removed by dissection and blotted dry, and a piece of the left lower lobe (about $300 \mathrm{mg}$ ) was weighed. This sample was homogenized in 20 volumes of $0.25 \mathrm{M}$ sucrose in $0.15 \mathrm{M} \mathrm{NaCl}$, $0.01 \mathrm{M}$ Tris-HCl, $0.001 \mathrm{M}$ EDTA buffer (pH 7.4), using a PotterElvehjem homogenizer surrounded by packed ice to prevent overheating. Then an equal volume of $1.05 \mathrm{M}$ sucrose in buffer was added to bring the concentration to $0.65 \mathrm{M}$ sucrose. The percentage of sucrose was adjusted to exactly $22.4 \%$, measured with a drop of solution in a hand-held refractometer (Fisher Scientific Co., Pittsburgh, PA). The material was then centrifuged in preweighed $17-\mathrm{mL}$ nitrocellulose tubes at $48000 \times g$ for 60 min at $4^{\circ} \mathrm{C}$ (Beckman L5-50B ultracentrifuge), the pellet being the fraction designated as IC, and the supernate containing the fractions designated as IA and IB. A measured aliquot of the supernate was diluted with buffer to $0.25 \mathrm{M}$ sucrose, the percentage of sucrose adjusted to exactly $8.6 \%$. This preparation was vortexed and again centrifuged at $48000 \times g$ for $60 \mathrm{~min}$ at $4^{\circ} \mathrm{C}$, the supernate being the IA fraction, and the pellet being the 
IB or tissue surfactant fraction. After decanting the supernate, the IB pellet was resuspended in $10 \mathrm{~mL}$ saline, $2 \mathrm{~mL}$ was extracted with $8 \mathrm{~mL}$ of $2: 1$ chloroform:methanol, and, after centrifugation at $1000 \times g$ at room temperature (Fisher Scientific, model no. 225), $1 \mathrm{~mL}$ of lower phase was assayed for phosphorus. Similarly, $2 \mathrm{~mL}$ of the IA supernate was extracted with chloroform:methanol and assayed for phosphorus. The results were expressed as $\mu$ g phospholipid/g wet lung.

The nitrocellulose tube was weighed again, and the IC pellet resuspended in saline and transferred to a glass tube. After centrifugation at $1000 \times g$ at room temperature and collection of the supernate, the IC pellet was homogenized in 20 volumes of 2:1 chloroform:methanol, using a Polytron homogenizer (Brinkmann Instruments Co., Westbury, NY). The homogenate was passed through filter paper (Whatman No. 1), and the volume of filtrate was measured. Then 0.2 volumes of saline were added, and the mixture vortexed and centrifuged at 1000 $\times g$ at $4^{\circ} \mathrm{C}$ (Beckman, model no. J2-21). After recording the volume of the lower phase, $0.1 \mathrm{~mL}$ was used in the phosphorus assay. In addition, the supernate from the above transfer process was also extracted with chloroform:methanol, and the amount in phosphorus assay was added to the IC fraction. The results were expressed as $\mu \mathrm{g}$ phospholipid/g wet lung.

Statistical analysis was performed using the Wilcoxon Signed Rank Sum Test (7). All data are reported as means \pm SEM.

\section{RESULTS}

There was a large increase in the IB surfactant fraction of lavaged lung in those treated with lanthanum (Table 1), $1002 \pm$ $90 \mu \mathrm{g}$ phospholipid/g wet lung, compared with $763 \pm 65 \mu \mathrm{g}$ phospholipid/g wet lung in those treated with saline alone $(p<$ 0.002 ). This suggests decreased secretion of tissue surfactant fraction during lavage with lanthanum. In addition, there was a significant increase in the IA fraction of those lavaged with lanthanum $(p<0.05)$.

In the two litters examined, the amount of phospholipid obtained by lavage with $10^{-3} \mathrm{M}$ lanthanum was only one fourth that obtained by lavage with saline alone, a significant difference $(p<0.05)$, suggesting a reduction in lavage-associated phospholipid secretion (Table 2).

\section{DISCUSSION}

Phospholipid secretion produced by lung distension may be studied in the 29.5-d newborn rabbit model, because little of the yield from lavage represents the alveolar surfactant pool and

Table 1. Surfactant (IB) and nonsurfactant (IA and IC) fractions of newborn rabbit lung tissue, after lavage with saline alone or $10^{-3} \mathrm{M}$ lanthanum*

\begin{tabular}{lccccc}
\hline & & \multicolumn{3}{c}{ Phospholipid ( $\mu \mathrm{g} / \mathrm{g}$ wet lung) } \\
\cline { 3 - 6 } & $n$ & Body wt $(\mathrm{g})$ & IA & IB & IC \\
\hline Saline & 21 & $48.7 \pm 1.9$ & $598 \pm 57$ & $763 \pm 65$ & $4293 \pm 368$ \\
Lanthanum & 21 & $49.5 \pm 1.7$ & $691 \pm 66 \dagger$ & $1002 \pm 90 \ddagger$ & $4375 \pm 278$ \\
\hline
\end{tabular}

$*$ Values are means \pm SEM. The data were obtained from seven litters. $\dagger p<0.05$ compared with saline controls.

$\ddagger p<0.002$ compared with saline controls. most of the yield represents fresh surfactant secretion induced by lavage (8). With lanthanum in the lavage solution, the phospholipid yield from lavage was only one fourth that with saline alone (Table 2), indicating a marked inhibition of lavage-induced surfactant secretion with lanthanum. This interpretation is confirmed by results for the tissue surfactant fraction (Table 1). If secretion is truly inhibited with lanthanum, there should be a significant increase in surfactant remaining in the lung tissue, as reflected in the IB fraction, after lavage with lanthanum. It was surprising to find also an increase in the IA fraction, which may mean that some surfactant was included in the IA fraction.

The procedure described by Frosolono (6) is a well-accepted method for isolating the surfactant fraction from lungs. The method used was that suggested for small samples; instead of collecting the IB fraction at the interface of a discontinuous sucrose gradient, the IB fraction was collected as a pellet after several centrifugations. The IA fraction, which floats in $0.25 \mathrm{M}$ sucrose, contains mainly light membranous material. The IB fraction, which floats in $0.65 \mathrm{M}$ sucrose, but sinks in $0.25 \mathrm{M}$ sucrose, is known to be enriched with membranous material, some of it having the configuration of lamellar bodies, the storage form of surfactant. This fraction has been shown to be highly surface active, and is not found in tissues other than the lung (6). Material that is heavy enough to sink in $0.65 \mathrm{M}$ sucrose, such as red cells and nuclei, is contained in the IC fraction. Neither the IA fraction nor the IC fraction is surface active.

The data in Table 2 do not give an exact estimate of the four fractions, IA, IB, IC, and lavage, because the units for the lavage fraction are different. However, inasmuch as the mean body weight was $51.6 \mathrm{~g}$ (Table 2) and 29.5-d rabbits have a lung weight/body weight ratio of 0.02 (9), it can be estimated that the mean lung weight was close to $1 \mathrm{~g}$, in which case the data for lavage phospholipid/lung are a good estimate for lavage phospholipid/g lung. Allowing for this small inaccuracy, the mean total phospholipid per gram of lung was $5650 \mu \mathrm{g}$ for lanthanumand $5540 \mu \mathrm{g}$ for saline-treated lungs (Table 2), values that agree closely. Despite this similarity in total lung phospholipid, it can be calculated that the distribution of the IB and lavage fractions was very different. The IB fraction for lanthanum-lavaged lungs represented $15 \%$ of total lung phospholipid, and the lavage fraction only $2.7 \%$. This compared with $10.4 \%$ for the IB fraction, but $11 \%$ for the lavage fraction, in those lavaged with saline alone. This difference in distribution reflects active secretion with saline lavage, but inhibited secretion during lavage with lanthanum.

The present method of isolating the tissue surfactant fraction has been widely used in adult animals (10) and with in vitro systems (11). Rieutort et al. (12) used a similar isolation method in fetal rats, but examined nonlavaged lungs. They found that at 0.93 gestation the surfactant fraction phospholipid represented $16.8 \%$ of total lung phospholipid, and at 0.98 gestation it represented $25.6 \%$ of total lung phospholipid. In our rabbit experiments with saline controls at 0.95 gestation, the sum of the IB fraction and the lavage fraction phospholipid, an estimate of total surfactant fraction, was $21.4 \%$ of the total lung phospholipid, which is in reasonable agreement with results from the rat.

One further observation is that the sum of the IB and lavage fraction phospholipid in pups treated with lanthanum was only $17.7 \%$ of total lung phospholipid (Table 2), less than in saline-

Table 2. Lung tissue and lung lavage fractions in newborn rabbits, lungs lavaged with saline alone or $10^{-3} \mathrm{M} \mathrm{lanthanum*}^{*}$

\begin{tabular}{lcccccc}
\hline & & \multicolumn{4}{c}{ Lung phospholipid } \\
\cline { 3 - 6 } & $n$ & BA & $\begin{array}{c}\text { IB } \\
(\mu \mathrm{g} / \mathrm{g} \text { wet lung })\end{array}$ & IC & $\begin{array}{c}\text { Lavage } \\
(\mu \mathrm{g} / \mathrm{lung})\end{array}$ \\
\hline Saline & 6 & $48.7 \pm 2.5$ & $409 \pm 40$ & $578 \pm 63$ & $3945 \pm 341$ & $608 \pm 109$ \\
Lanthanum & 6 & $54.5 \pm 3.3$ & $481 \pm 44$ & $847 \pm 107$ & $4169 \pm 302$ & $153 \pm 40 \dagger$ \\
\hline
\end{tabular}

\footnotetext{
* Values are means \pm SEM. The data were obtained from the first two litters of the seven litters reported in Table 1.
}

$\dagger p<0.05$ compared with saline controls. 
treated controls. It is possible that the lung synthesized more surfactant during lavage with saline alone, because secretion was so active, or, alternatively, after treatment with lanthanum, some of the IB fraction was transferred to the IA or IC fractions. The latter interpretation is supported by the observation that in the lanthanum-treated pups there was a significant increase in the IA fraction (Table 1). This suggests that the increased IB fraction after lanthanum treatment may be an underestimate of the true magnitude of the change, and may explain why the increase in the IB fraction appeared to be less than the decrease in the lavage fraction after treatment with lanthanum (Table 2).

It is concluded that lanthanum inhibits surfactant secretion stimulated by lung distension during lavage. This was demonstrated by a reduction in lavage phospholipid and by an increase in the residual tissue surfactant phospholipid.

\section{REFERENCES}

1. Hildebran JN, Goerke J, Clements JA 1981 Surfactant release in excised rat lung is stimulated by air inflation. J Appl Physiol 51:905-910

2. Corbet A, Gross J, Frink J, Rudolph J 1986 Calcium dependence of phospholipid secretion in fetal rabbit lungs. Pediatr Res 20:185A(abstr)

3. Weiss BG, Goodman FR 1969 Effects of lanthanum on contraction, calcium distribution and $\mathrm{Ca}^{45}$ movements in intestinal smooth muscle. J Pharmacol Exp Ther 169:46-55

4. Corbet A, Voelker R, Murphy F, Owens M 1991 Effect of calcium and calcium antagonists on phospholipid secretion induced by lung inflation in newborn rabbits. Am J Med Sci 301:102-114

5. Corbet AJS, Flax P, Alston C, Rudolph AJ 1978 Effect of aminophylline and dexamethasone on secretion of pulmonary surfactant in fetal rabbits. Pediatr Res 12:797-799

6. Frosolono MF 1982 Broncho-alveolar fluid and subcellular surfactant fractions. In: Farrell PM (ed) Lung Development: Biological and Clinical Perspectives Vol 1, Biochemistry and Physiology. Academic Press, New York, pp 111134

7. Langley R 1974 Practical Statistics. Drake Publishers, New York.

8. Corbet AJ, Kolni HW, Perreault T, Frink J, Rudolph AJ 1985 Development of beta-adrenergic control of phospholipid secretion in rabbit lung. $J$ Appl Physiol 58:2011-2019

9. Corbet AJS, Flax P, Rudolph AJ 1976 Reduced surface tension in lungs of fetal rabbits injected with pilocarpine. J Appl Physiol 41:7-14

10. Sanders RL, Longmore WJ 1975 Phosphatidylglycerol in rat lung. II. Comparison of occurrence, composition and metabolism in surfactant and residual lung fractions. Biochemistry 14:835-840

11. Engle MJ, Sanders RL, Douglas WHJ 1980 Type II alveolar cells in organotypic culture: model system for the study of surfactant synthesis. Biochim Biophys Acta 717:225-236

12. Rieutort M, Farrell PM, Engle MJ, Pignol B, Bourbon JR 1986 Changes in surfactant phospholipids in fetal rat lungs from normal and diabetic pregnancies. Pediatr Res 20:650-654 